doi:10.1016/j.jcv.2006.01.017

Copyright (c) 2006 Elsevier B.V. All rights reserved.

\title{
European seroepidemiology network 2: Standardisation of assays for seroepidemiology of varicella zoster virus
}

\section{Fernando de Ory ${ }^{a}, *$, José Manuel Echevarría ${ }^{a}$, George Kafatos ${ }^{b}$, Cleo Anastassopoulou ${ }^{c}$, Nick Andrews ${ }^{b}$, Josephine Backhouse ${ }^{d}$, Guy Berbers ${ }^{e}$, Blazena Bruckova ${ }^{f}$, Daniel I. Cohen ${ }^{\text {, Hester de Melker }}{ }^{\text {, }}$, Irja Davidkin ${ }^{\text {, }}$, Giovanni Gabutti, ${ }^{i}{ }^{1}$, Louise M. Hesketh ${ }^{j}$, Kari Johansen ${ }^{k}$, Sari Jokinen ${ }^{\text {h }}$, Lindsay Jones', Anika Linde ${ }^{k}$, Elisabeth Miller ${ }^{b}$, Joël Mossong ${ }^{m}$, Anthony Nardone ${ }^{b}$, Maria Cristina Rota ${ }^{n}$, Andreas Sauerbrei ${ }^{\circ}$, François Schneider ${ }^{m}$, Zahava Smetana ${ }^{p}$, Annedore Tischer ${ }^{q}$, Athanassios Tsakris ${ }^{c}$ and Robert Vranckx'}

${ }^{a}$ Centro Nacional de Microbiología, Instituto de Salud Carlos III, Majadahonda, Madrid, Spain

${ }^{\mathrm{b}}$ Health Protection Agency, London, United Kingdom

'University of Athens, Athens, Greece

${ }^{\mathrm{d} N a t i o n a l}$ Centre for Immunisation Research and Surveillance, Westmead, Australia

${ }^{\mathrm{e}}$ Rijksinstituut voor Volksgezondheid en Milieu, Bilthoven, The Netherlands

${ }^{f}$ National Public Health Institute, Bratislava, Slovakia

${ }^{9}$ Sackler Faculty of Medicine Tel Aviv University and Israel Center for Disease Control, Israel

${ }^{\mathrm{h}}$ National Public Health Institute, Helsinki, Finland

'Department of Medical and Experimental Medicine, University of Ferrara, Italy ${ }^{j}$ Lancashire Teaching Hospitals, NHS Trust, Preston, Lancashire, United Kingdom ${ }^{k}$ Swedish Institute for Infectious Disease Control, Solna, Sweden

'Virus Reference Laboratory, Dublin, Ireland

mLaboratoire National de Santé, Luxembourg

${ }^{\mathrm{n}}$ Istituto Superiore di Sanità, Roma, Italy

${ }^{\circ}$ Institut für Virologie and Antivirale Therapie, Universtätsklinikum, Jena, Germany

${ }^{\mathrm{p} T h e}$ Chaim Sheba Medical Center, Tel Hashomer, Israel

${ }^{9}$ Robert Koch Institut, Berlin, Germany

${ }^{r}$ Institute of Public Health, Brussels, Belgium

* Corresponding author at: Servicio de Microbiología Diagnóstica, Centro Nacional de Microbiología, Instituto de Salud Carlos III, Majadahonda 28220, Spain. Tel.: +34 91 8223630; fax: +34915097966.

${ }^{1}$ Formerly Lab of Hygiene, University of Lecce.

\section{Abstract}

\section{Background}

The aim of the European Sero-Epidemiology Network (ESEN2) is to harmonise the serological surveillance of vaccine-preventable diseases in Europe.

\section{Objective}

To allow comparison of antibody prevalence in different countries by standardising results into common units. 


\section{Study design}

For varicella zoster virus (VZV), a reference laboratory established a panel of 148 samples, characterised by indirect enzyme-immunoassay (ELISA), indirect immunofluorescence, and complement fixation test. Fifty-seven samples were also studied by the fluorescence antibody to membrane antigen test. The geometric mean of the antibody activity (GMAA) obtained from four ELISA determinations was used to characterise each sample of the panel as positive (GMAA: >100 mIU/ml), equivocal (GMAA: $50-100 \mathrm{mIU} / \mathrm{ml}$ ) or negative (GMAA: $<50 \mathrm{mIU} / \mathrm{ml}$ ) for antibody to VZV (anti-VZV). Thirteen laboratories, using five different ELISA tests, tested the panel.

\section{Results}

Agreement with the reference laboratory was above $85 \%$ in all cases, and the $R^{2}$ values obtained from regression analysis of the quantitative results were always higher than 0.87. Finally, the regression equations could be used to convert national values into a common unitage.

\section{Conclusion}

This study confirmed that results for anti-VZV obtained by different ELISA methods can be converted into common units, enabling the comparison of the seroprevalence profiles obtained in the participant countries.

Keywords: Varicella zoster virus; Seroepidemiology; Standardisation; ELISA; Indirect immunofluorescence; Fluorescent antibody to membrane antigen

\section{Introduction}

The European Seroepidemiology Network 2 (ESEN2) was established in 2001 as a continuation of a previous project (ESEN) (Osborne et al., 1997). Both programmes were partly funded by the European Commission. The main objective of the project was the harmonisation of serological procedures used by the national laboratories for detecting antibodies to vaccine-preventable diseases caused by both viruses (rubella, measles, mumps, hepatitis A and $B$, and varicella zoster) and bacteria (diphtheria and pertussis), in order to compare the results obtained in the corresponding national serosurveys.

Enzyme-immunoassay (ELISA) tests have been recognized as useful methods to detect antibody to varicella zoster virus (anti-VZV) for epidemiological purposes (Larussa et al., 1987, Weinberg et al., 1996 and Doern et al., 1997). Variations in both sensitivity and specificity have been, however, found with commercial antiVZV assays (Larussa et al., 1987, Weinberg et al., 1996 and Doern et al., 1997). In addition, inter-laboratory comparisons have confirmed significant variations in results (de Ory et al., 2004a). Surveys of the VZV seroprevalence have been performed in Europe using different antibody assays, so that a standardisation procedure was required. The aim of the present collaborative work was to develop such a procedure for results obtained in VZV antibody surveys performed by 14 European countries. 


\section{Material and methods}

\subsection{Standardisation procedure}

The methods used for deriving the standardisation equations are based on the methodology developed for the original ESEN project (Andrews et al., 2000) and are described in detail elsewhere (Kafatos et al., 2005). In brief, a reference laboratory (Centro Nacional de Microbiología, Majadahonda, Madrid, Spain) prepared a standardisation panel containing enough sera to include results from the whole range of antibody levels from negative and equivocal (or low positive) to positive samples. The panel was then sent to each participant laboratory where it was tested by the method of their choice as long as assay results were reported as quantitative titres whenever possible, even when reading outside the normal assay limits. For the purpose of the analysis, results above the upper detection limit were arbitrarily doubled and those below the lower detection limit were halved (Andrews et al., 2000, Giammanco et al., 2003 and von Hunolstein et al., 2000). The same procedure was repeated halfway through testing the main serum bank and these panel results were used for the selection of a regression equation that could be used to standardise each country's main bank results into the reference country's units.

There were occasions when it was not possible to standardise a country's results because the main serum bank was tested before the distribution of the panel. An alternative method of standardisation was then used named 'backstandardisation' (Kafatos et al., 2005). A panel of approximately 150 samples was selected randomly from the main serum bank after stratifying the samples equally by result (positive, equivocal, negative). The samples were sent to the reference laboratory to be tested. The standardisation was then performed in the same way used for the standardisation panel.

Seven participants (Australia, Belgium, Finland, Ireland, Israel, The Netherlands and Slovakia) tested the panel twice, once before and a second time during the testing of the main bank. The remaining six countries (Germany, Greece, Italy, Luxembourg, Sweden and United Kingdom) tested the panel once (Table 1). From these, Greece and Sweden only participated for the purposes of method comparison. Germany, Italy and United Kingdom had already completed the testing of the main serum bank before the panel was constructed, so they performed back-standardisation.

Table 1.

ELISAs for detection of anti-VZV IgG used by country

\begin{tabular}{|l|l|l|l|}
\hline Country & No. of tests & Assay & Range reported titres (IU/mI) \\
\hline Australia & 2 & Dade Behring & - \\
\hline Belgium & 2 & Dade Behring & $\leq 178$ \\
\hline Finland & 2 & Dade Behring & - \\
\hline Germany & Back-standardisation & Dade Behring & $\geq 0.05$ \\
\hline Greece & 1 & Dade Behring & - \\
\hline Ireland & 2 & DiaMedix & - \\
\hline
\end{tabular}




\begin{tabular}{|c|c|c|c|}
\hline Country & No. of tests & Assay & Range reported titres $(\mathrm{IU} / \mathrm{ml})$ \\
\hline Israel & 2 & Dade Behring & - \\
\hline Italy & Back-standardisation & Dade Behring & $0.05-8.5$ \\
\hline Luxembourg & 1 & Dade Behring & - \\
\hline The Netherlands & 2 & Human & $<2$ \\
\hline Slovakia & 2 & Euroimmun & - \\
\hline Spain & & Reference & \\
\hline Sweden ${ }^{a}$ & 1 & In-house & - \\
\hline UK & Back-standardisation & DiaMedix & - \\
\hline
\end{tabular}

${ }^{a}$ Quality assurance only.

\subsection{Preparation reference panel}

A panel of 148 serum samples was established using residual samples from a Virology laboratory (Centro Nacional de Microbiología, Majadahonda, Madrid, Spain). Samples were sent either for diagnosis of VZV-associated disease or for determination of immunity against VZV and therefore are not representative of the Spanish general population. Initially, samples were selected and classified on the basis of a single ELISA result for anti-VZV IgG (Enzygnost VZV, Dade Behring, Germany) and were as follows:

i. 48 negative samples.

ii. 13 equivocal samples.

iii. 20 samples either positive (18 samples) or equivocal (2 samples) for anti-VZV IgG and positive for VZV specific IgM.

iv. 12 samples from six cases with seroconversion, or significant rise in titer, as detected by the complement fixation test (CFT). Three cases converted from negative to positive and two from equivocal to positive for anti-VZV IgG by ELISA, the remaining testing positive in both samples.

v. 52 positive samples.

vi. A series of three dilutions of a single positive sample diluted in negative sample (two positive and one equivocal for anti-VZV by ELISA).

All samples were subsequently tested four times for anti-VZV IgG by ELISA and the geometric mean of the antibody activity (GMAA) was calculated. The panel samples were finally classified as negative (GMAA: $<50 \mathrm{mIU} / \mathrm{ml}, 60$ samples), equivocal (GMAA: $50-100 \mathrm{mIU} / \mathrm{ml}$, four samples) or positive (GMAA:

$>100 \mathrm{mIU} / \mathrm{ml}, 84$ samples). All samples tested negative for Hepatitis B surface antigen (HBsAg) and Hepatitis C Virus antibody (Vitros ECi, Ortho Clinical Diagnostics), and human immunodeficiency viruses 1 and 2 antibody (Genelavia Mixt, Sanofi Pasteur), ensuring biosafety. Each sample then was divided into 15 aliquots of $40-50 \mu$ l that were frozen at $-70^{\circ} \mathrm{C}$ until distribution to participants. 


\subsection{Serological methods}

i. ELISA. A commercial test designed to detect anti-VZV IgG (Enzygnost VZV IgG, Dade Behring, Germany) was used to characterise all the panel samples. Samples were tested as described by the manufacturer. The kit uses both antigen and control antigen wells, and samples were tested diluted 1:231. An absorbance increment $(\Delta A)$ was calculated for each sample by subtracting the optical density (OD) of the control antigen well from the corresponding OD of the antigen well. The specific antibody activity (SAA) was established according to the formula: $\log 10 \mathrm{mIU} / \mathrm{ml}=a \Delta A^{\beta}$, where $a$ and $\beta$ were constants specific of the reagent's batch, and samples were considered positive (SAA: $>100 \mathrm{mIU} / \mathrm{ml}$ ), equivocal (SAA: $50-100 \mathrm{mIU} / \mathrm{ml}$ ) or negative (SAA: $<50 \mathrm{mIU} / \mathrm{ml}$ ) for anti-VZV IgG according to the SAA values. Two replicas of a positive control, with SAA expressed in $\mathrm{mIU} / \mathrm{ml}$, were included in each plate.

ii. Indirect immunofluorescence (IIF). A commercial method for measuring antiVZV IgG (Virgo, USA) was used. The assay was carried out as described by the manufacturer. Samples were tested diluted 1:8. Once the assay was completed, the slides were mounted and read at $400 \times$ under a fluorescence-inverted microscope (Axiovert 25, Zeiss, Jena, Germany) equipped with a mercure lamp (HBO50). A sample was considered positive for anti-VZV IgG when the intensity of the fluorescence was equal or higher than the fluorescence given by an endpoint dilution of a positive control that was tested in each run. Two samples gave an indeterminate pattern of fluorescence, so results could be obtained from 146 samples.

iii. Fluorescent antibody to membrane antigen (FAMA) test. The FAMA test was performed at the Institute of Virology and Antiviral Therapy, Friedrich-Schiller University of Jena on a group of 57 randomly selected samples, using a standard procedure (Sauerbrei et al., 2004). Samples were titrated from the 1:2 dilution.

iv. CFT was performed by a standard procedure (Grist et al., 1979), using antigen from a commercial source (Virion, Switzerland). Samples were titrated from a 1:8 dilution.

\subsection{Participants}

The panel was tested by the following laboratories: National Centre for Immunisation Research and Surveillance (Westmead, Australia); Institute of Public Health (Brussels, Belgium); National Public Health Institute (Helsinki, Finland); Robert Koch Institute (Berlin, Germany); School of Health Sciences, University of Athens (Athens, Greece); Virus Reference Laboratory (Dublin, Ireland); Central Virology Laboratory, The Chaim Sheba Medical Center (Tel Hashomer, Israel); Laboratory of Hygiene, University of Lecce; Laboratoire National de Santé (Luxembourg); Rijksinstituut voor Volksgezondheid en Milieu (Bilthoven, The Netherlands); National Public Health Institute (Bratislava, Slovak Republic); Swedish Institute for Infectious Disease Control (Solna, Sweden); Lancashire Teaching Hospitals NHS Trust (Preston, Lancashire, United Kingdom); and Instituto de Salud Carlos III (Majadahonda, Spain), acting as reference laboratory as well. All the participants used ELISA methods for anti-VZV IgG testing. These methods are specified in Table 1. 


\subsection{Data analysis}

After the first testing of the panel results were plotted against those of the reference country, any extreme results were investigated and the proportion of the variance explained by different regression lines was calculated $\left(R^{2}\right)$. A meeting took place including all the participant laboratories to discuss these preliminary findings and identify any methodological problems with the assays.

The results from the second panel test were compared with the results from the first test investigating potential assay drifts. The choice of the standardisation equation was based on the panel that was tested during the main bank results using the methods previously described (Kafatos et al., 2005). In order to have successfully standardised results it is important that (a) the regression line fits the data well around the equivocal range and (b) the percentage of variance explained by the model is high $\left(R^{2}\right.$ should be at least 0.8$)$.

\section{Results}

\subsection{Qualitative comparisons}

The agreement for overall positive and negative results obtained before the standardisation by each participant laboratory in relation to ELISA reference results, are shown in Table 2 . The overall agreement of the ELISA results ranged from $85.8 \%$ (Slovakia) to $98.6 \%$ (The Netherlands). The agreement for positives ranged from $76.1 \%$ (Slovakia) to $100 \%$, and for negatives from $66.7 \%$ (Sweden) to $100 \%$. For laboratories using the same ELISA as the reference laboratory (Dade Behring), the overall agreement ranged from $89.9 \%$ (Israel) to $98 \%$ (Italy). The values for positives ranged from $85.2 \%$ to $100 \%$, and for negatives from $75 \%$ to $100 \%$. Table 2 shows a comparison of the national results against the qualitative results obtained by IIF in the reference laboratory. The overall agreement ranged from $69.9 \%$ to $93.2 \%$, for positives from $60.4 \%$ to $93.8 \%$, and for negatives from $91.4 \%$ to $100 \%$.

Table 2.

Qualitative comparison of national pre-standardised ELISA results against the reference criterion (GMAA in four determinations of ELISA, Dade Behring), and against the IIF results obtained in the reference laboratory

\begin{tabular}{|c|c|c|c|c|c|c|c|}
\hline \multirow[t]{3}{*}{ Country } & \multirow[t]{3}{*}{ Assay } & \multicolumn{6}{|c|}{ Agreement between national and reference centre } \\
\hline & & \multicolumn{3}{|c|}{ Reference criterion } & \multicolumn{3}{|l|}{ IIF } \\
\hline & & $\begin{array}{l}\text { Overall } \\
\% \\
(N=148)\end{array}$ & $\begin{array}{l}\text { Positives } \\
\% \\
(N=88)\end{array}$ & $\begin{array}{l}\text { Negatives } \\
\% \\
(N=60)\end{array}$ & $\begin{array}{l}\text { Overall } \\
\% \\
(N=146)\end{array}$ & $\begin{array}{l}\text { Positives } \\
\% \\
(N=111)\end{array}$ & $\begin{array}{l}\text { Negatives } \\
\% \\
(N=35)\end{array}$ \\
\hline Australia & Dade Behring & 93.9 & 100 & 85.0 & 89.0 & 85.6 & 100 \\
\hline Belgium & Dade Behring & 91.2 & 85.2 & 100 & 74.7 & 66.7 & 100 \\
\hline Finland & Dade Behring & 97.3 & 100 & 93.3 & 85.6 & 81.1 & 100 \\
\hline Germany & Dade Behring & 97.3 & 98.9 & 95.0 & 84.9 & 80.2 & 100 \\
\hline Greece & Dade Behring & 93.9 & 100 & 85.0 & 86.7 & 84.7 & 97.1 \\
\hline Ireland $^{\mathrm{a}}$ & DiaMedix & 96.6 & 94.3 & 100 & 80.0 & 73.6 & 100 \\
\hline
\end{tabular}


Journal of Clinical Virology Volume 36, Issue 2, June 2006, Pages 111-118

\begin{tabular}{|c|c|c|c|c|c|c|c|}
\hline \multirow[t]{3}{*}{ Country } & \multirow[t]{3}{*}{ Assay } & \multicolumn{6}{|c|}{ Agreement between national and reference centre } \\
\hline & & \multicolumn{3}{|c|}{ Reference criterion } & \multicolumn{3}{|l|}{ IIF } \\
\hline & & $\begin{array}{l}\text { Overall } \\
\% \\
(N=148)\end{array}$ & $\begin{array}{l}\text { Positives } \\
\% \\
(N=88)\end{array}$ & $\begin{array}{l}\text { Negatives } \\
\% \\
(N=60)\end{array}$ & $\begin{array}{l}\text { Overall } \\
\% \\
(N=146)\end{array}$ & $\begin{array}{l}\text { Positives } \\
\% \\
(N=111)\end{array}$ & $\begin{array}{l}\text { Negatives } \\
\% \\
(N=35)\end{array}$ \\
\hline Israel & Dade Behring & 89.9 & 100 & 75.0 & 93.2 & 91.8 & 100 \\
\hline Italy & Dade Behring & 98.0 & 96.6 & 100 & 81.5 & 75.7 & 100 \\
\hline Luxembourg & Dade Behring & 91.9 & 100 & 80.0 & 91.8 & 89.2 & 100 \\
\hline The Netherlands & Human & 98.6 & 98.9 & 98.3 & 85.6 & 81.1 & 100 \\
\hline Slovakia & Euroimmun & 85.8 & 76.1 & 100 & 69.9 & 60.4 & 100 \\
\hline Spain & Dade Behring & \multicolumn{3}{|l|}{ REFERENCE } & 83.6 & 78.4 & 100 \\
\hline Sweden & In house & 86.5 & 100 & 66.7 & 92.5 & 93.8 & 91.4 \\
\hline United Kingdom & DiaMedix & 95.3 & 94.3 & 96.7 & 80.1 & 74.8 & 97.1 \\
\hline
\end{tabular}

${ }^{a}$ Results on 147 samples (87 positives and 60 negatives) against reference criterion, and 145 samples, against IIF (110 positives and 35 negatives).

Fifty-seven samples from the panel were tested by FAMA. Using a FAMA cut-off titre of $1: 2$, there was $100 \%$ agreement of positives and $36 \%$ of negatives (Table 3 ). However, if the negative titre was lowered to $1: 8$ there was $94 \%$ agreement of positives and $84 \%$ of negatives (Table 3 ). The 16 positive samples classified as negative with a FAMA titre of $1: 2$, gave titres of $1: 2$ (two samples), $1: 4$ (10 samples) or $1: 8$ (four samples) (geometric mean titre, GMT: 4.36). Two equivocal samples were also positive by FAMA (titres: $1: 2$ and 1:8), and all the positive samples tested positive in FAMA, with titres of $1: 4$ (one sample), 1:8 (six samples), 1:16 (six samples), 1:32 (three samples), 1:64 (one sample), 1:128 (two samples), 1:256 (two samples), 1:512 (five samples), 1:1024 (one sample), and $1: 2048$ (three samples) (GMT:

\begin{tabular}{|c|c|c|c|}
\hline & \multicolumn{3}{|l|}{ ELISA } \\
\hline & Positives & Equivocals & Negatives \\
\hline \multicolumn{4}{|c|}{ FAMA $1: 2$} \\
\hline POS & 30 & 2 & 16 \\
\hline NEG & 0 & 0 & 9 \\
\hline \multicolumn{4}{|c|}{ Agreement for ELISA positives: $100 \%(32 / 32)$} \\
\hline \multicolumn{4}{|c|}{ Agreement for ELISA negatives: $36 \%(9 / 25)$} \\
\hline \multicolumn{4}{|c|}{ FAMA $1: 8$} \\
\hline POS & 29 & 1 & 4 \\
\hline NEG & 1 & 1 & 21 \\
\hline \multicolumn{4}{|c|}{ Agreement for ELISA positives: $93.8 \%(30 / 32)$} \\
\hline Agree & ent for ELI & A negatives: & $4 \%(21 / 25)$ \\
\hline
\end{tabular}
68.59).

Table 3.

Comparison between results obtained by ELISA (Dade Behring) in the reference laboratory and by FAMA on 57 randomly selected samples from the reference panel 


\subsection{Quantitative comparisons}

The panel was tested twice by seven laboratories and agreement between first and second tests was good (fitted line close to the unit line). A problem with the Belgium tests comparison was solved after testing an extra panel. For Israel there was a downward drift giving slightly higher results on the first than the second panel (average differences was 0.09 on the log 10 scale).

The panel chosen for the standardisation and the chosen regression lines are given in Fig. 1. A quadratic model was chosen for all the standardisation equations with the exception of Ireland where a linear line was preferred. The random panels generated from the main bank chosen for back-standardisation are given separately in Fig. 2 .
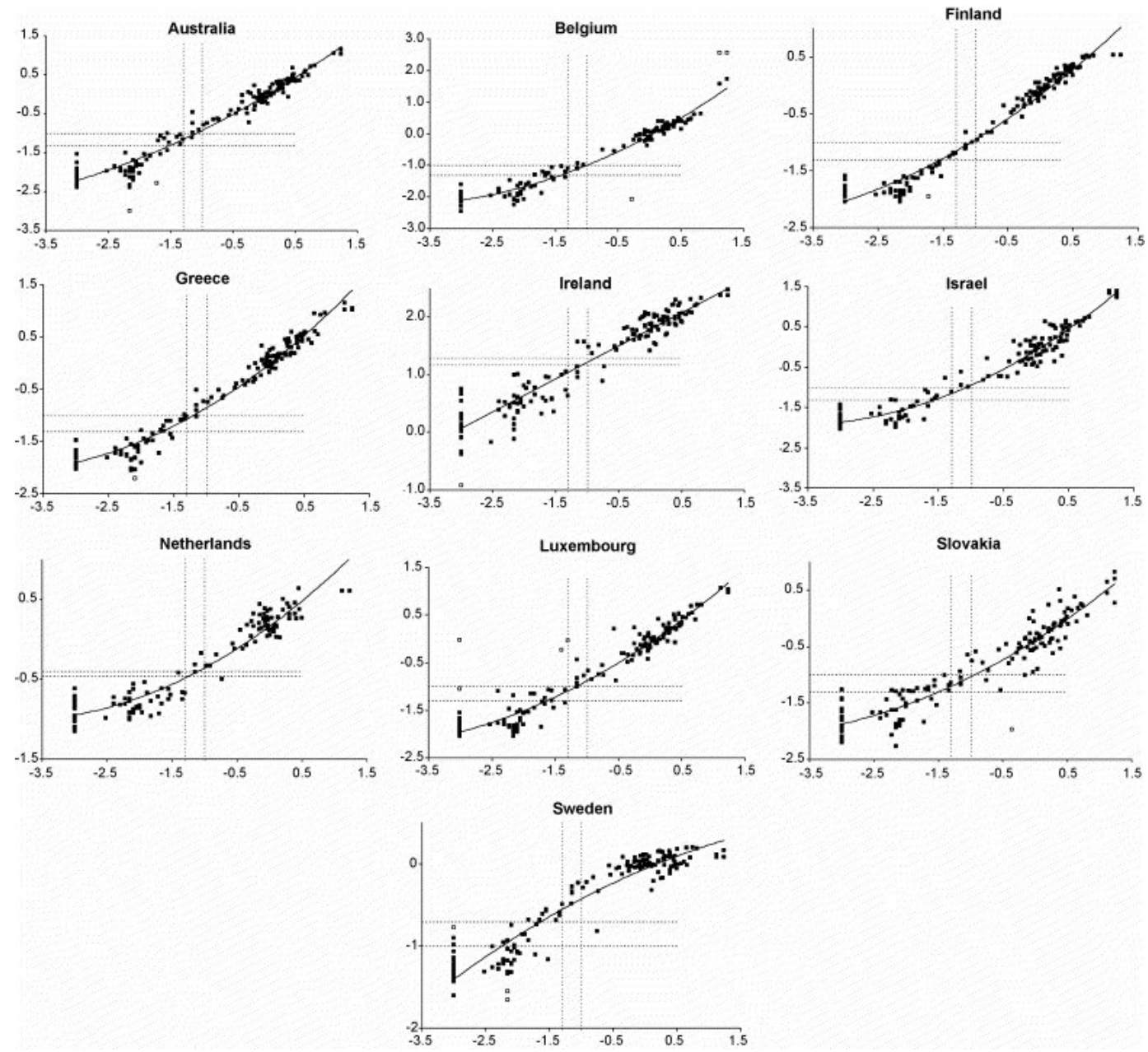

Fig. 1. ELISA results of the reference panel obtained by country ( $y$-axis) and plotted against the ELISA results of the Spanish reference laboratory ( $x$-axis) on the log 10 scale. Open squares denote any outliers, dotted lines picture the equivocal ranges and solid lines are the regression models. 

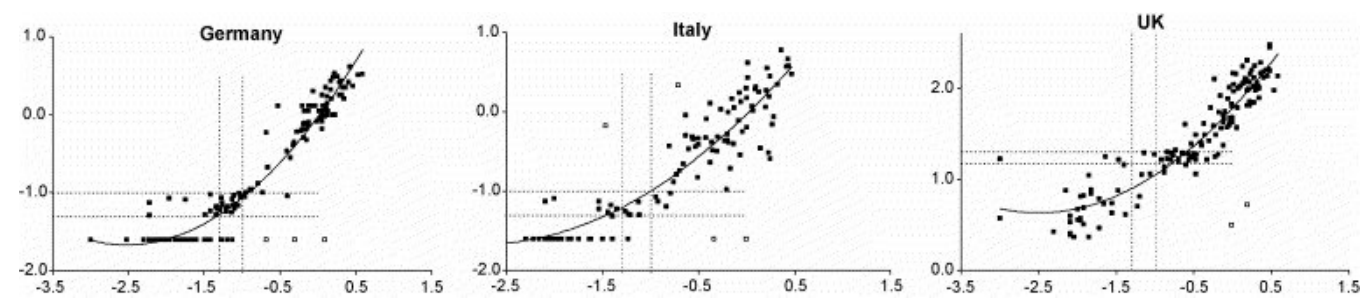

Fig. 2. ELISA results of back-standardisation by country ( $y$-axis) plotted against the ELISA results of the Spanish reference laboratory ( $x$-axis) on the log 10 scale. Open squares denote any outliers, dotted lines picture the equivocal ranges and solid lines are the regression models.

The investigation for outliers showed a number of samples that were extreme in individual country comparisons with the reference laboratory. These results were excluded from the country's regression (Fig. 1 and Fig. 2).

Laboratories provided quantitative results wherever possible, which limited the problem of arbitrary results i.e. "censored data". An investigation did not show evidence of important influence of these censored data on the standardisation equations in any of the countries examined (Kafatos et al., 2005).

The standardisation equations together with the $R^{2}$ values are given in Table 4 . The $R^{2}$ was naturally lower for laboratories that used the method of backstandardisation but was generally very high and well above 0.80 (Kafatos et al., 2005). The classification of the non-standardised results and the standardised results using the reference centre's equivocal range is given in Table 4. For most countries, the line of best fit passed close to the point of equivalence, so that standardisation had little impact on the final sero-profiles from each country. But in three countries (Greece, Luxembourg and Sweden), the local assay overestimated titres in comparison to the reference centre and for one country (UK) there was an over-estimation of titres (Table 4 and Fig. 1 and Fig. 2).

Table 4.

Standardisation equations by country

\begin{tabular}{|l|l|l|l|l|l|}
\hline Country & $\begin{array}{l}\text { Test run used } \\
\text { for } \\
\text { standardisation }\end{array}$ & Standardisation equation & $R^{2}$ & \multicolumn{2}{l|}{ Equivocal range in local units } \\
\hline & & & & $\begin{array}{l}\text { Pre- } \\
\text { standardisation }\end{array}$ & $\begin{array}{l}\text { Post- } \\
\text { standardisation }\end{array}$ \\
\hline Australia & 2nd & $y=0.08 x^{2}+0.94 x-0.07$ & 0.96 & $0.05-0.10$ & $0.03-0.08$ \\
\hline Belgium & 2nd & $y=0.13 x^{2}+1.06 x-0.07$ & 0.97 & $0.05-0.10$ & $0.04-0.10$ \\
\hline Finland & 2nd & $y=0.08 x^{2}+0.86 x-0.17$ & 0.97 & $0.05-0.10$ & $0.03-0.08$ \\
\hline Germany & Back-std & $y=0.26 x^{2}+1.30 x-0.03$ & 0.95 & $0.05-0.10$ & $0.05-0.12$ \\
\hline Greece ${ }^{a}$ & 1st & $y=0.11 x^{2}+0.98 x+0.01$ & 0.97 & $0.05-0.10$ & $0.02-0.06$ \\
\hline Ireland & 2nd & $y=0.57 x+1.79$ & 0.91 & $0.15-0.20$ & $0.08-0.14$ \\
\hline Israel & 2nd & $y=0.14 x^{2}+1.00 x-0.08$ & 0.95 & $0.05-0.10$ & $0.03-0.08$ \\
\hline Italy & Back-std & $y=21 x^{2}+1.18 x-0.03$ & 0.87 & $0.05-0.10$ & $0.04-0.10$ \\
\hline
\end{tabular}




\begin{tabular}{|c|c|c|c|c|c|}
\hline \multirow[t]{2}{*}{ Country } & \multirow{2}{*}{$\begin{array}{l}\text { Test run used } \\
\text { for } \\
\text { standardisation }\end{array}$} & \multirow[t]{2}{*}{ Standardisation equation } & \multirow[t]{2}{*}{$R^{2}$} & \multicolumn{2}{|c|}{ Equivocal range in local units } \\
\hline & & & & $\begin{array}{l}\text { Pre- } \\
\text { standardisation }\end{array}$ & $\begin{array}{l}\text { Post- } \\
\text { standardisation }\end{array}$ \\
\hline Luxembourg & $1 \mathrm{st}$ & $y=0.09 x^{2}+0.90 x-0.08$ & 0.95 & $0.05-0.10$ & $0.02-0.08$ \\
\hline The Netherlands & $2 \mathrm{nd}$ & $y=0.08 x^{2}+0.60 x+0.16$ & 0.92 & $0.35-0.40$ & $0.04-0.06$ \\
\hline Slovakia & 2 nd & $y=0.08 x^{2}+0.82 x-0.39$ & 0.90 & $0.05-0.10$ & $0.03-0.11$ \\
\hline Sweden $^{a}$ & $1 \mathrm{st}$ & $y=-0.04 x^{2}+0.33 x-0.06$ & 0.91 & $0.10-0.20$ & $0.0016-0.0058$ \\
\hline UK & Back-std & $y=0.18 x^{2}+0.92 x+1.78$ & 0.88 & $0.07-0.10$ & $0.0008-0.0017$ \\
\hline
\end{tabular}

${ }^{a}$ Quality assurance only.

\section{Discussion}

For all participating laboratories satisfactory standardisation equations were obtained that explained most of the variability $\left(R^{2}>0.87\right)$. Therefore, the main serum bank results can be successfully standardised by applying the equations and converting the results into reference centre's units.

Although there were a few outliers for some countries these constituted a small percentage of the panel (maximum 3.4\%). In some countries standardisation had little effect on the qualitative results (Belgium, Finland, Germany, The Netherlands, Ireland, Italy, Luxembourg), whereas in others the effect was much larger (Australia, Israel, Slovakia, UK).

Three countries tested their results using back-standardisation (Germany, Italy and UK). The variability explained by the model $\left(R^{2}\right)$ for these countries was lower than in those not using back-standardisation. Germany and Italy were the only countries that did not report titres below the usual assay negative cut-off since these results were obtained a long time ago and it was not possible to obtain quantitative measurements. This demonstrates the importance of obtaining quantitative results throughout the whole range of the assay for epidemiological studies.

Testing of serum samples for anti-VZV can be performed by different assays, including ELISA, IIF, FAMA and latex agglutination. FAMA is currently recognized as a gold standard and has been used as a reference to evaluate the performance of other assays. The high sensitivity of FAMA is likely due to the preservation of the structure of the viral glycoproteins in the surface of live, VZV-infected cells, which is thought to allow the assay to detect neutralizing antibody (Grose et al., 1983). FAMA is cumbersome to perform and requires experienced technicians, since the readout is subjective, so that it is impractical for epidemiological purposes. IIF and ELISA have shown a good correlation with FAMA in comparative studies and are considered valid alternatives to FAMA for these purposes (Landry et al., 1987).

Two recent studies showed that $58 \%$ to $88 \%$ of samples giving equivocal results by the Dade Behring's anti-VZV IgG commercial ELISA tested positive by FAMA at a low dilution (1:2) (Heininger et al., 2001 and Wutzler et al., 2002), as well as did $15 \%$ (3 out of 20) of the ELISA-negative samples (Wutzler et al., 2002). The results obtained on a subset of 57 samples from the panel constructed in the 
present study confirmed these findings and showed that more than $50 \%$ of the samples testing negative by the Dade Behring's ELISA displayed a low antibody titre by FAMA, and also showed that most of these titres were below 1:8.

Considering the practical aspects of FAMA and the lack of standardised procedures for this test, whether these discrepancies represent true falsenegative results of the ELISA is difficult to assess. Usually, testing of specific antibody by IIF for diagnostic purposes is performed on sample dilutions equal to, or greater than 1:8. Using this common approach, the agreement between ELISA and FAMA rose significantly in the present study, but a $16 \%$ of ELISA-negative, FAMA-positive samples (4 out of 25) were still found. Whether these differences in sensitivity may, in practical terms, affect significantly the results obtained in a serosurvey of anti-VZV in a given population will depend on the real prevalence of the infection in that population or in each particular age group. Considering the high prevalence of the VZV infection in Europe, it is unlikely that such differences may constitute a practical problem for public health management at present. Most of the serosurveys of anti-VZV performed in Europe have been done, however, with the Dade Behring's ELISA (Salleras et al., 2000, Heininger et al., 2001, Gabutti et al., 2001, Wutzler et al., 2002, Thiry et al., 2002 and de Ory et al., 2004 b), for which the sensitivity found in this study was not lower than $85 \%$. A recalculation of the age-specific prevalences obtained in one of these studies (de Ory et al., 2004b) showed variations less than $1.1 \%$ in all age groups, so that the practical impact of this comparative low sensitivity does not seem relevant for epidemiological surveys at this time.

Comparison of the results obtained by ELISA in the participant laboratories with those obtained by both ELISA and IIF in the reference laboratory showed consistently lower sensitivity figures when IIF results were taken as a reference (see Table 2). This difference was mainly due to the finding of low titre, IIFpositive samples among those giving equivocal results in the Dade Behring's ELISA. These findings agree with those observed in the subset of samples tested by FAMA and suggest that most of the Dade Behring's ELISA-equivocal samples contain low levels of anti-VZV IgG. It seems, therefore, sensible to recommend that equivocal results obtained by that assay in seroepidemiological surveys are recorded as positive in regard to calculation of prevalence figures.

With a single exception, the participants of this collaborative study used commercial ELISA methods that can be automated. With these methods, the overall agreement, as the agreement in the positives and negatives were mostly above $80 \%$. In addition, discrepancies were mainly found on samples for which the true anti-VZV status was difficult to assess, since IIF and/or FAMA results discrepant with the reference result were obtained. As an example, the 12 falsepositive results reported by Luxembourg were on samples testing negative by IIF and/or FAMA. These observations were especially frequent in the records from Sweden, with 20 positive results among the 60 negative panel members. Sixteen of them tested positive by IIF and 9 out of 10 tested positive by FAMA, suggesting, therefore, that the Swedish ELISA has a sensitivity equivalent to FAMA and IIF. Anyway, the use of assays with lower sensitivity could not be recommended for certain clinical situations, such as the detection of vaccineinduced seroconversions.

This study shows that results for anti-VZV obtained by various ELISA methods in different laboratories can be converted into a common unitage using the reference panel method. This means that any likely differences observed between countries' seroprevalence profiles must be for reasons other than laboratory 
methodology, e.g. epidemiology or sampling method for the main serum bank.

\section{Acknowledgements}

This project was partially funded by a grant from the Directoriate Research of the European Commission QLK2-CT-2000-00542. Further sources of funding: CRPSanté (Luxembourg); ISCIII MPY1075/01 (Spain).

We wish to thank for assistance to I. Deitemeier and V. Wagner (Germany); S. Koliou (Greece); A. Marina (Israel); P. Crovari, M. Quattrocchi, S. Salmaso (Italy); L. Pütz (Luxembourg); I. Tcherniaeva and P. van Gageldonk (The Netherlands); M. P. Balfagón and M. E. Guisasola (Spain).

\section{References}

Andrews et al., 2000 N. Andrews, R.G. Pebody, G. Berbers, C. Blondeau, P. Crovari and I. Davidkin et al., The European Sero-Epidemiology Network: standardizing the enzyme immunoassay results for measles, mumps and rubella, Epidemiol Infect 125 (2000), pp. 127-141.

de Ory et al., 2004a F. de Ory, J.C. Sanz, J.E. Echevarría, M. Mosquera and M.E. Guisasola, y Red de Laboratorios Autonómicos para el Plan de Eliminación del Sarampión. IgM específica frente al virus del sarampión. Estudio de intercomparación de los laboratorios del Plan para la Eliminación del Sarampión, Enferm Infecc Microbiol Clin 22 (2004), pp. 319-322.

de Ory et al., 2004b F. de Ory, R. Ramírez, L. García Comas, P. León, M.J. Sagües and J.C. Sanz, Is there a change in cytomegalovirus seroepidemiology in Spain?, Eur J Epidemiol 19 (2004), pp. 85-89.

Doern et al., 1997 G.V. Doern, L. Robbie and R. St. Amand, Comparison of the Vidas and BioWhittaker enzyme immunoassays for detecting IgG reactive with varicella-zoster virus and mumps virus, Diagn Microbiol Infect Dis 28 (1997), pp. 31-34.

Gabutti et al., 2001 G. Gabutti, C. Penna, M. Rossi, S. Salmaso, M.C. Rota, A. Bella et al. and Serological Study Group, The seroepidemiology of varicella in Italy, Epidemiol Infect 126 (2001), pp. 433-440.

Giammanco et al., 2003 A. Giammanco, A. Chiarini, P.A. Maple, N. Andrews, R. Pebody and N. Gay et al., European Sero-Epidemiology Network: standardisation of the assay results for pertussis, Vaccine 22 (2003), pp. 112-120.

Grist et al., 1979 N.R. Grist, E.J. Bell and E.A.C. Follett, Urquhart GED diagnostic methods in clinical virology (3rd ed.), Blackwell Scientific Publications, Oxford (1979) p. 95-115.

Grose et al., 1983 C. Grose, D.P. Edwards, W.E. Friedrichs, K.A. Weigle and W.L. McGuire, Monoclonal antibodies against three major glycoproteins of varicella-zoster virus, Infect Immun 40 (1983), pp. 381-388.

Heininger et al., 2001 U. Heininger, C. Braun-Fahrländer, D. Desgrandchamps, J. Glaus, L. Grize, P. Wutzler et al. and The Scarpol Team, Seroprevalence of varicella zoster virus immunoglobulin G antibodies in Swiss adolescents and risk factor analysis for seronegativity, Pediatr Infect Dis J 20 (2001), pp. 775-778.

Kafatos et al., 2005 G. Kafatos, N. Andrews and A. Nardone, Model selection methodology for interlaboratory standardisation of antibody titres, Vaccine 23 (2005), pp. 5022-5027 (on behalf of the ESEN2 project).

Landry et al., 1987 M.L. Landry, S.D. Cohen, D.R. Mayo, C.K. Fong and W.A. Andiman, Comparison of fluorescent-antibody-to-membrane-antigen test, indirect immunofluorescence assay, and a commercial enzyme-linked immunosorbent assay for determination of antibody to varicella-zoster virus, J Clin Microbiol 25 (1987), pp. 832-835. 
Larussa et al., 1987 P. Larussa, S. Steinberg, E. Waithe, B. Hanna and R. Holzman, Comparison of five assays for antibody to varicella-zoster virus and the fluorescent-antibody-to-membrane-antigen test, J Clin Microbiol 25 (1987), pp. 2059-2062.

Osborne et al., 1997 K. Osborne, J. Weinburg and E. Miller, The European Seroepidemiology Network, Eurosurveillance 2 (1997), pp. 29-31.

Salleras et al., 2000 L. Salleras, A. Domínguez, J. Vidal, P. Plans, M. Salleras and J.L. Taberner, Seroepidemiology of varicella zoster virus infection in Catalonia (Spain). Rationale for universal vaccination programmes, Vaccine 19 (2000), pp. 183-188.

Sauerbrei et al., 2004 A. Sauerbrei, I. Farber, A. Brandstadt, M. Schacke and P. Wutzler, Immunofluorescence test for sensitive detection of varicella-zoster virus-specific IgG: an alternative to fluorescent antibody to membrane antigen test, J Virol Meth 119 (2004), pp. 25-30.

Thiry et al., 2002 N. Thiry, P. Beutels, R. Vranckx, C. Vandermeulen, M.V. Wielen and P.V. Damme, The seroepidemiology of primary varicella zoster virus infection in Flanders, Eur J Pediatr 161 (2002), pp. 588-593.

von Hunolstein et al., 2000 C. von Hunolstein, H. Aggerbeck, N. Andrews, G. Berbers, F. FievetGroyne and P.A. Maple et al., European Sero-Epidemiology Network: standardisation of the results of diphtheria antitoxin assays, Vaccine 18 (2000), pp. 3287-3296.

Weinberg et al., 1996 A. Weinberg, A.R. Hayward, H.B. Masters, I.A. Ogu and M.J. Levin, Comparison of two methods for detecting varicella-zoster virus antibody with varicella-zoster virus cell-mediated immunity, J Clin Microbiol 34 (1996), pp. 445-446.

Wutzler et al., 2002 P. Wutzler, I. Farber, S. Wagenpfeil, H. Bisanz and A. Tischer, Seroprevalence of varicella zoster virus in the German population, Vaccine 20 (2002), pp. 121-124. 